\title{
Squamous cell carcinoma arising in ovarian mature cystic teratoma: report of three cases
}

\author{
Bashyal $\mathrm{R}^{1}$, Lee $\mathrm{MC}^{1}$ \\ ${ }^{1}$ Department of Pathology, BP Koirala Memorial Cancer Hospital, Chitwan, Nepal
}

\section{Keywords: \\ Neoplastic transformation; Ovary; \\ Squamous cell carcinoma; Teratoma}

\begin{abstract}
Malignant transformation of mature cystic teratoma of the ovary is rare. A wide variety of malignant tumors may arise within benign mature cystic teratoma. The most common form of malignant transformation of a mature cystic teratoma is squamous cell carcinoma. We report a series of three cases that developed squamous cell carcinoma in a benign ovarian cystic teratoma. Two of the carcinomas occurred in postmenopausal women: 51-year-old (case \# 2) and 60 year-old (case \# 3). The first case occurred in a 33-year-old woman. Histologically, all three cases were moderately differentiated squamous cell carcinomas and were confined to the ovaries. The aim of this study was to review our experience with this disease and to review the literature.
\end{abstract}

\section{INTRODUCTION}

Mature cystic teratoma (MCT) of the ovary accounts for $10 \%-20 \%$ of all ovarian neoplasm with bilateral involvement in $10-15 \%$ of the cases. Malignant transformation develops in less than $2 \%$ of MCT. ${ }^{1}$ Approximately $75 \%$ of malignancies arising in cystic teratomas are invasive or rarely in situ squamous cell carcinomas (SCC), followed by adenocarcinoma (7\%), and sarcoma $(7 \%))^{2,3}$ We report three cases of SCC arising in MCT.

\section{CASE REPORT}

\section{CASE \# 1}

A 33 year-old-female presented with lower abdomen pain and distension for 4 months. Per vaginal examination revealed mass in the left adnexae rendering the clinical

\section{Correspondence:}

Dr. Reeta Devi Poneru (Bashyal)

Department of Pathology, BP Koirala Memorial Cancer Hospital

Chitwan, Nepal

Email:rdbashyal@hotmail.com impression of ovarian tumor. Preoperative diagnosis of carcinoma ovary and tense ascites was made by ultrasonography. Peritoneal fluid cytology was negative for malignancy. CA 125 level was 24.19U/ml (reference range 0.00-35.00U/ml). Hysterectomy with bilateral salpingooophorectomy was performed. On gross examination the uterus, cervix, bilateral fallopian tubes and right ovary were normal. Left ovary was enlarged, measured $15 \times 12 \times 11 \mathrm{~cm}$. External surface was irregular with ruptured tumor capsule. Cut surface showed a unilocular cyst with predominant solid areas. The cyst wall was thickened and irregular. The cyst was filled with pultaceous material and plug of hair. Histopathological examination of the cyst revealed an invasive SCC in a pre-existing MCT (fig. 1A) infiltrating and extending beyond the tumor capsule but limited to the ovary.

\section{CASE \# 2}

A 51 year-old-female presented with pain in the lower abdomen for 3 months. Per vaginal examination revealed central pelvic mass. The cervix was not visualized, however 


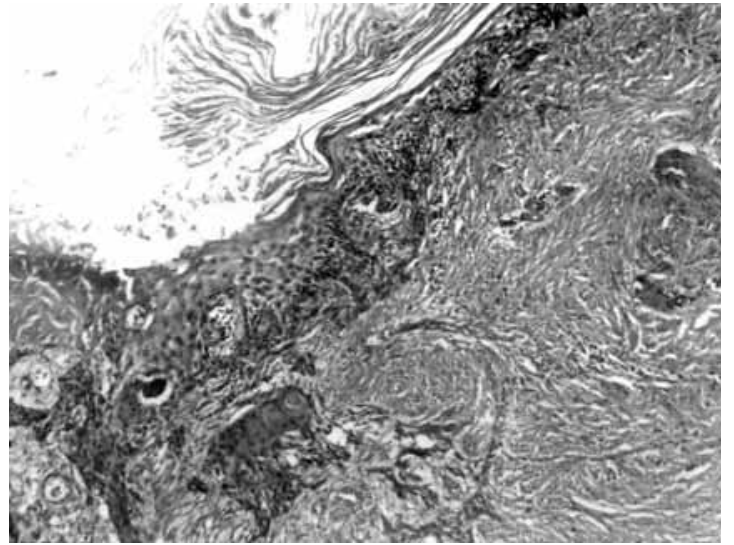

Figure 1A: Cyst wall with benign squamous epithelium lining on the right and malignant tumor cells on the left with stromal invasion (X20)

the vault appeared normal. Preoperative diagnosis of left tubo-ovarian mass by ultrasonography and infected ovarian mass was rendered clinically. Hysterectomy with bilateral salpingo-oophorectomy was performed. On gross examination the uterus, cervix, bilateral fallopian tubes and right ovary were normal. Left ovary was enlarged, measured $14 \times 9 \times 5 \mathrm{~cm}$. External surface was smooth and the tumor capsule was intact. Cut surface showed a unilocular cyst containing waxy sebaceous material, tuft of hair and solid areas. Histopathological examination of the cyst demonstrated sheets of malignant squamous cells (fig.1B) in a MCT infiltrating but not extending beyond the tumor capsule. Mitoses were frequent and lymphovascular tumor embolus was present.

\section{CASE \# 3}

A 60 year-old-female underwent exploratory laparotomy with abdominal hysterectomy and bilateral salpingooophorectomy in one of the peripheral hospital. On gross examination the uterus, cervix, bilateral fallopian tubes and left ovary were normal. Myometrium of uterus showed multiple fibroids, the largest measuring $3.5 \mathrm{~cm}$ in diameter. Right ovary was enlarged, measured 10x9x4 cm. External surface was smooth with an intact tumor capsule. Cut surface showed a unilocular cyst filled with greasy material and hair and had solid areas. Its wall was markedly thickened $(2 \mathrm{~cm})$. Histopathological examination of the cyst revealed cyst wall lined by squamous epithelium with its appendages and partly by respiratory epithelium and underlying cartilage (fig. 2). Nests and sheets of malignant squamous cells were seen in the ovarian stroma infiltrating but not extending beyond the tumor capsule. Myometrium of the uterus showed benign leiomyomata.

\section{DISCUSSION}

SCC arising from MCT is a rare pathologic event and in most instances not diagnosed preoperatively. There are

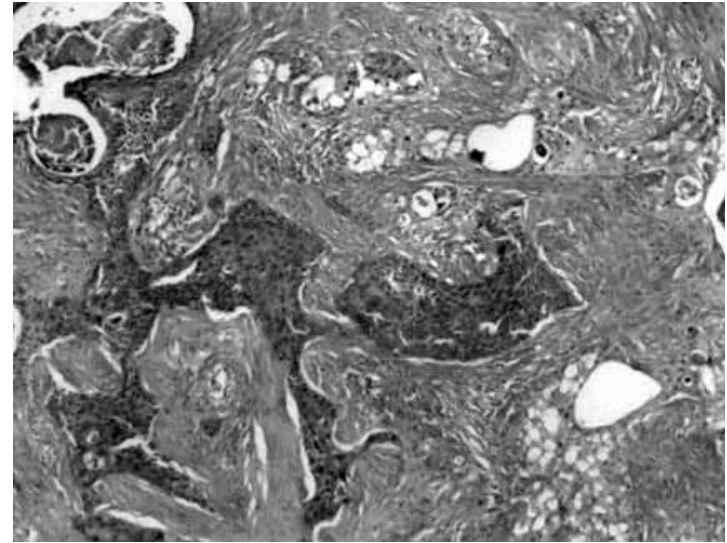

Figure 1B: Islands of malignant squamous cells invading the stroma without a clear border with adipocytes (X 20)

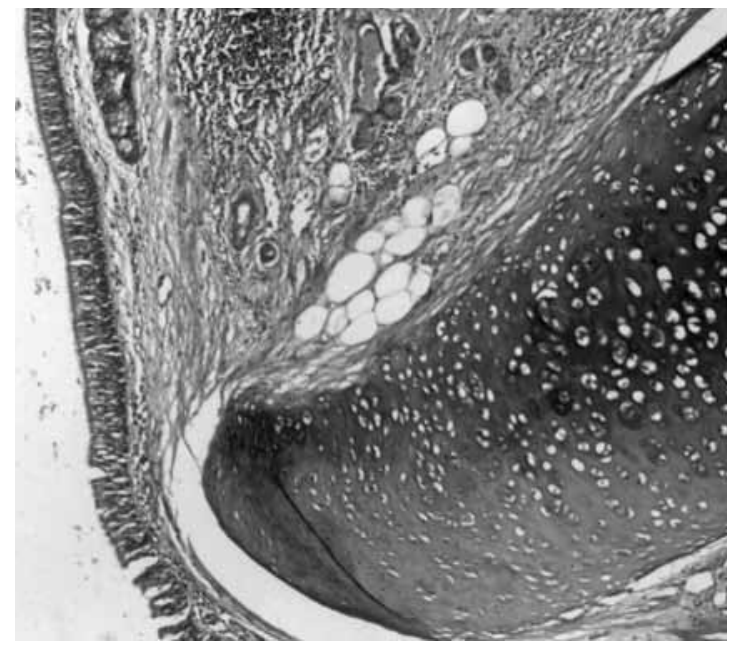

Figure 2: Mature Cystic Teratoma of Ovary: Respiratory mucosa with adipocytes, cartilage and smooth muscle fibers (X20)

no particular signs or symptoms which are characteristic of malignancy arising in a dermoid cyst. ${ }^{4}$ Malignant transformation of MCT is an uncommon complication, and usually occurs in postmenopausal women, although it has been sometimes reported in young patients around 30 years of age. ${ }^{5,6}$ In contrast, a MCT usually occur in women of reproductive age. ${ }^{7}$ Teratomas include tissues originating from three different germ cell layers, and all of those tissues have the potential to undergo malignant transformation. The most common malignancy arising in MCT is SCC, representing $75 \%$ followed by adenocarcinoma (7\%), and sarcoma $(7 \%) .{ }^{2,3}$ As SCC arising in MCT is quite rare, one must exclude metastasis particularly from the cervix. Stromal invasion by malignant appearing epithelium should be used as definite criteria for categorizing MCT with malignant transformation. ${ }^{8}$ Histologically, all the three cases in our study showed conventional moderately differentiated SCC with nests and sheets of malignant squamous cells invading the ovarian stroma. In a study by Mee $\mathrm{J}$ et al, the dominant histological grade was well to moderately differentiated 
SCC. ${ }^{1}$ Lymphovascular tumor embolus was noted in case \# 2 in this series. The common presenting symptoms in two patients were abdominal pain and distension in one case although this presentation is not characteristic for malignant transformation in MCT. In our study two of the carcinomas occurred in postmenopausal women, 51(case \# 2) and 60 (case \# 3) years of age while case \# 1 occurred in a 33 year young female patient. The size of the tumor is an important factor to predict malignant transformation. As reported by Kikkawa et $\mathrm{al}^{9}$ and in some more studies tumors with diameter greater than $10 \mathrm{~cm}$ are associated with increased risk of malignancy. ${ }^{10}$ The mean age of the patients in our study was 48 years and the mean tumor size was $13 \mathrm{~cm}$. Similar fingidng was observed in other study. ${ }^{11}$ Several previous studies have reported prognosis of malignant MCT to be quite poor. However better prognosis has been reported with squamous differentiation and with tumor confined to the ovary. ${ }^{12}$ Factors that carry an unfavourable prognosis is higher FIGO stage, cyst wall invasion, rupture, tumor dissemination, ascites, adhesion, tumor grade, growth pattern, vascular invasion and tumor type other than SCC. ${ }^{13}$

\section{CONCLUSION}

Factors predicting malignant transformation of MCT are increasing age, large tumor size, and solid portions in MCT. This entity should be diagnosed only after thorough search for primary focus of SCC elsewhere is made to rule out a possibility of metastasis into the ovary.

\section{REFERENCES}

1. Mee J, Nae MH, Kyung KY, Lee KH, Chae CY, Lee ES. Squamous Cell Carcinoma arising from Mature Cystic Teratoma of the Ovary. A report of three cases. Korean J Pathol 1999;33:1211-5.

2. Maslin P, Luchs JS, Haas J, Katz DS. Ovarian teratoma with malignant transformation: CT diagnosis. Am J Roentgenol 2002;178:1574.

3. Lai PF, Hsieh SC, Chein JC, Fang CL, Chan WP, Yu C. Malignant transformation of an ovarian mature cystic teratoma: computed tomography findings. Arch Gynecol Obstet 2005;271:355-7.

4. Torbaghan SS, Aleagha ME, Sedighi S et al. Archives of Iranian Medicine 2009;12:187.

5. Kurtz JE, Jaeck D, Maloisel F, Jung GM, Chenard MP, Dufour P. Combined modality treatment for malignant transformation of a benign ovarian teratoma. Gynecol Oncol 1999;73:319-21.

6. Wen KC, Hu WM, Twu NF, Chen P, Wang PH. Poor prognosis of intraoperative rupture of mature cystic teratoma with malignant transformation. Taiwan J Obstet Gynecol 2006;45:253-6.

7. Rha SE, Byun JY, Jung SE et al. Atypical CT and MRI manifestations of mature cystic teratomas. Am J Roentgenol 2004;183:743-50.

8. Gupta V, Sood N. Squamous cell carcinoma arising in a mature cystic teratoma. Indian J Pathol Microbiol 2009;52:271-3.

9. Kikkawa F, Nawa A, Tamakoshi $\mathrm{K}$ et al. Diagnosis of squamous cell carcinoma arising from mature cystic teratoma of the ovary. Cancer 1998;82:2249-55

10. Yamanaka Y, Tateiwa Y, Miyamoto H et al. Preoperative diagnosis of malignant transformation in mature cystic teratoma of the ovary. Eur J Gynecol Oncol 2005;26:391-2.

11. Bal A, Mohan H, Singh S.B. Malignant transformation in mature cystic teratoma of the ovary: report of five cases and review of the literature. Arch Gynecol Obstet 2007;275:179-182.

12. Comerci JT Jr, Licciardi F, Bergh PA et al. Mature cystic teratoma: A clinicopathologic evaluation of 517 cases and review of the literature. Obstet Gynecol. 1994;84:22-8.

13. Park JY, Kim DY, Kim JH, Kim YM, Kim YT, Nam JH. Malignant transformation of mature cystic teratoma of the ovary: experience at a single institution. Eur J Obstet Gynecol Reprod Biol 2008;141:173-8. 